\title{
Voto e avaliação do Plano Real em 1998
}

Paulo Sérgio da Silva

\section{Resumo}

O objetivo, neste trabalho, é explicar o voto dos eleitores, na eleição presidencial de 1998, por meio da avaliação de custo e benefício do Plano Real. A literatura está centrada nas teorias econômicas que focalizam o voto como resultado da escolha racional dos indivíduos. A fonte de dados é uma pesquisa realizada pelo Núcleo de Relações Internacionais (NUPRI), da Universidade de São Paulo. As técnicas estatísticas empregadas baseiam-se na construção de tabelas e cálculo dos coeficientes de associação, Phi e V de Cramér.

\section{Voto e economia}

Na década de sessenta muitas das análises buscaram investigar a associação entre o voto e a economia. Kramer (1971), Nordhauss (1975) e Monroe (1976) pressupunham que o eleitor tinha a capacidade de avaliar se a economia ia bem ou mal e também de responsabilizar e punir os governantes pelas políticas econômicas através do voto. No Brasil, país que passou por vários planos econômicos e teve a primeira reeleição de sua história em 1998 - após o sucesso do Plano Real -, essa discussão da relação entre economia e voto revelase oportuna.

O objetivo deste trabalho é explicar a escolha eleitoral através do voto por avaliação de custo e benefício econômico do Plano Real. A 
literatura baseia-se nas teorias da escolha racional de explicação do voto que focalizam os eleitores enquanto racionais, votando de acordo com os custos e benefícios. Compreende-se que estas teorias se dividem em correntes e modelos específicos de explicação do voto.

Este trabalho fez uso de um banco de dados ${ }^{1}$ de uma pesquisa sobre a eleição presidencial brasileira de 1998, realizada pelo Núcleo de Pesquisa em Relações Internacionais (NUPRI), da Universidade de São Paulo. A metodologia utilizada baseia-se na construção de tabelas e no cálculo do coeficiente de associação entre as variáveis, Phi.

Os tópicos do trabalho são três. No primeiro discute-se a bibliografia sobre o comportamento eleitoral, focalizando apenas os autores ligados à "teoria economicista" e à "teoria econômica dowsiana" da explicação do voto. No segundo tópico constrói-se o contexto da eleição de 1998. O terceiro e último tópico é o centro do trabalho, no qual se testa as hipóteses de associação entre as variáveis em estudo.

\section{Comportamento eleitoral}

Resolvemos, para simplificar a compreensão da literatura, que as teorias da escolha racional de explicação econômica do voto podem ser agrupadas em duas correntes principais: "teoria economicista" $e$ "teoria econômica downsiana". ${ }^{2}$ Esta última se trata do modelo apresentado por Downs (1999), em sua obra Uma Teoria Econômica da Democracia.

1 Gostaria de agradecer aos pesquisadores do Núcleo de Pesquisa em Relações Internacionais (NUPRI), pela concessão do banco de dados da pesquisa sobre a eleição presidencial de 1998, coordenada pelo professor José Augusto Guilhon Albuquerque.

2 Outras teorias de explicação do voto, fora do eixo do nosso referencial teórico, fazem parte da escola psicológica de Michigan (ver Campbell, Angus et alli., 1980). 


\section{1. "Teoria economicista" da explicação do voto}

Uma corrente conhecida, dentro da "teoria economicista", na qual se enquadra os autores Kramer (1971), Nordhauss (1975) e Tufte (1975), é a "teoria do voto cíclico" (political business cycles). Segundo esta vertente, os líderes do governo lançariam mão de variáveis macroeconômicas, como o controle da inflação e do desemprego, para expandir a economia durante os períodos eleitorais e obter os votos dos eleitores, os quais por sua vez, avaliariam positivamente os benefícios econômicos. De maneira inversa, após as eleições, a economia retornaria ao estágio anterior. Segundo os autores desta corrente este tipo de manipulação econômica, por parte do governo, acaba gerando crises cíclicas na economia.

Outra corrente é a teoria do "pocketbook voting" e do "sociotropic voting". A primeira concebe que o eleitor toma como referência sua situação financeira pessoal e a segunda que o eleitor avalia a situação nacional do país.

Segundo Figueiredo (1991), baseado em Kramer (1971), as correntes da "teoria economicista" podem ser reunidas numa única vertente: o "modelo economicista" de explicação do voto. Cada indivíduo, isoladamente no seu microcosmo, reage e age de acordo com o que está acontecendo com a economia do país. O eleitor atua como um árbitro, punindo e retribuindo os governantes.

De acordo com Kramer os autores do "modelo economicista" não aceitam a racionalidade plena do eleitor como pressupõe Downs. Kramer (1971), segundo Figueiredo (1991), sugere que a regra de decisão seguida pelos eleitores baseia-se em informações prontamente disponíveis para todos, ou seja, o desempenho passado dos governantes ou do partido a que eles pertencem. De posse dessa informação, os eleitores poderão avaliar os candidatos de acordo com a sua situação social e econômica, e julgar se "vale a pena" manter a atual "equipe" de governantes, ou se é melhor mudar (Figueiredo, 1991: 74-86).

"Se o desempenho do partido no governo for 'satisfatório' de acordo com algum padrão simples, os eleitores votam para mantê-lo no governo permitindo que continuem a implementar políticas; se o desempenho for considerado não-satisfatório, os eleitores votam contra o partido situacionista, dando uma chance à oposição". (Kramer, 1971: 134) 
Dessa regra de decisão decorrem duas proposições que constituem o ponto de partida para a explicação do comportamento político-eleitoral nessa teoria:

\section{Proposição 1:}

As respostas aos apelos oposicionistas variam inversamente com o grau de satisfação do eleitorado com os atuais governantes.

\section{Proposição 2:}

As respostas aos apelos situacionistas variam diretamente com o grau de satisfação do eleitorado com os atuais governantes.

(Kramer, 1971, citado por Figueiredo, 1991: 74-86)

A partir dessas proposições conclui-se que os insatisfeitos tendem a aderir mais rapidamente às teses oposicionistas do que os satisfeitos.

A versão economicista do eleitor racional concebe o cidadãoeleitor segundo as seguintes premissas:

1. o ator racional vê o voto como uma escolha entre (apenas) duas políticas: a que está em vigor e uma outra, alternativa;

2. a base que os eleitores usam para avaliar o desempenho dos governantes é sua situação social, de seu grupo de referência;

3. a principal causa de sua situação pessoal, ou de seus pares, está no desempenho individual ou partidário dos governantes, descontando os fatores econômicos idiossincráticos responsáveis por eventuais fracassos ou sucessos pessoais;

4. o critério de decisão do eleitor está no grau de satisfação que ele obtém do desempenho dos governantes.

(Kramer, 1971, op. cit. Figueiredo, 1991: 74-86)

Em resumo, a "teoria economicista" do comportamento eleitoral concebe a formação das preferências eleitorais individuais como uma função da avaliação que os eleitores fazem dos governos relativamente a seu bem-estar. 


\section{2. "Teoria Econômica" da Explicação do Voto}

Segundo Downs (1999) o eleitor avalia os custos e benefícios antes de votar. Além disso, o eleitor maximiza seu voto, isto é, vota no candidato ou partido que lhe trará mais benefícios no futuro.

Antes de maximizar seu voto, o eleitor faz um julgamento das ações passadas dos governos no qual avalia o desempenho das políticas do governo, dentre elas a econômica, para, somente depois, decidir se vale a pena ou não votar no governo ou na oposição. Para Downs o voto baseado na avaliação do desempenho do governo é o "voto retrospectivo" e o voto que maximiza as expectativas de lucro no futuro é o "voto prospectivo". Segundo Fiorina (1981) o "voto retrospectivo" de Downs é um meio para o "voto prospectivo".

Para Downs (1999) os candidatos e partidos agem com o objetivo de maximizar os votos dos eleitores. Eles formulam políticas, elaboram planos econômicos, para que o eleitor faça boa avaliação de seus governos, reelegendo-os.

É claro que este modelo vale em um espaço eleitoral competitivo de uma democracia. O governo persegue seu objetivo de se reeleger sob uma estrutura democrática que permite a existência de partidos de oposição, bem como uma atmosfera de graus de variáveis de incerteza e de eleitores racionais (Downs, 1999: 41).

O governo é definido por Downs como aquele agente especializado na divisão de trabalho que pode impor suas decisões sobre todos os outros agentes ou indivíduos na área. Um governo democrático é aquele escolhido periodicamente por meio de eleições populares nas quais dois ou mais partidos competem pelos votos de todos os adultos (Downs, 1999: 56).

Um partido é definido como uma equipe de indivíduos que procuram controlar o aparato de governo através da obtenção de cargo numa eleição, "Sua função na divisão do trabalho é formular e executar políticas governamentais sempre que conseguir chegar ao poder" (Downs, 1999: 56). A principal meta do partido é ganhar a eleição, logo todas as ações dos partidos objetivam a maximização dos votos. O partido trata as políticas como meios para alcançar esse fim.

Toda eleição torna-se, assim, um mecanismo de sinalização como um selecionador de governo. "A eleição é um julgamento feito sobre a folha de serviços do partido no poder" (Downs, 1999: 62). 
Podemos concluir, portanto, que, para Downs, os partidos não representam classes e que o voto do indivíduo é uma escolha individual. A ideologia dos partidos seria uma linguagem sintética, representando um atalho que economiza custos de informação para o eleitor, assim como o "voto retrospectivo", em que o eleitor faz julgamento das ações passadas dos governos.

\section{Conclusão}

De acordo com a revisão da literatura realizada por Figueiredo (1991), a distinção entre a "teoria economicista" e a "teoria econômica" do voto está no sentido instrumental, da escolha da ação.

A participação eleitoral implica, no mínimo, três alternativas: não participar; participar votando em "A"; participar votando em "B". Diante dessa situação, o eleitor pode comportar-se de duas maneiras diferentes: ter um comportamento maximizante, no sentido dowsiano, sempre que escolher a alternativa que produza o melhor resultado; ou escolher, entre as alternativas disponíveis, aquela que garanta minimamente a satisfação de seus interesses (Monroe, 1976: 162, Figueiredo, 1991). Tal distinção marca a fronteira entre essas duas linhas de investigação. Ambas pressupõem um eleitor racional, em oposição ao eleitor psicológico, michiganiano. No entanto, a pura noção de satisfação de interesses retira do comportamento humano o elemento de cálculo estratégico, deixando apenas o elemento de avaliação entre custos e benefícios (Figueiredo, 1991: 71).

Para o modelo dowsiano, o comportamento humano é maximizante; para o modelo economicista, o comportamento humano é "satisfacionista", satisficing behavior (Figueiredo, 1991: 71-2).

Portanto, para Downs, a questão é, além da avaliação entre custos e benefícios, a maximização dos ganhos. Para o "modelo economicista" é a satisfação de cada indivíduo.

Neste trabalho entendemos que tanto para o "modelo economicista", quanto para a teoria econômica de Downs, o eleitor é racional e avalia o desempenho econômico de um governo passado preocupado com custos e benefícios pessoais. A nossa preocupação se restringe ao que há em comum entre o "modelo economicista" e a "teoria econômica" de Downs e não diferente, testando apenas o semelhante, isto é, 
a avaliação que os eleitores fazem dos custos e benefícios ou, no caso deste trabalho, a avaliação do Plano Real. Para ir mais longe e saber se o voto dos eleitores é "satisfacionista" ou "maximizante" seria necessário um outro banco de dados sobre a eleição de 1998, que contivesse questões que nos permitissem medir essas variáveis. No entanto, esperamos que, pelo menos, o nosso esforço presente possa revelar se o eleitor vota de acordo com avaliação de custos e benefícios do Plano Real, preocupado com seu bolso ("pocketbook voting"), ou com a situação do país ("sociotropic voting").

\section{Estudos Nacionais ${ }^{3}$}

Dentro da literatura nacional destacamos muitos autores que focalizam de diversas maneiras a relação entre economia e voto. Dentre esses trabalhos, podemos ressaltar o de Santos (1988). O autor entende que o sucesso dos governos (medido em popularidade ou taxa de reeleição) está relacionado ao desempenho macroeconômico. Duas variáveis econômicas são as mais importantes, a inflação e o desemprego. Se o governo tiver como manipular ou influenciar estas duas variáveis macroeconômicas de interesse, maiores as chances de reeleição.

Muszynski e Mendes (1990) analisam dados de "surveys" relativos ao período 1974/89, apontando o peso da avaliação do desempenho econômico do governo no comportamento do eleitor. Isso já teria ocorrido no período autoritário com o fim do "milagre econômico". No período atual, os autores destacam o desgaste dos governos estaduais peemedebistas (1983/86) e do governo Sarney com os planos econômicos (Cruzado II, Bresser e Verão).

Mendes e Venturi (1994), analisando a eleição presidencial de 1994, mostram uma inversão brutal de tendências de voto entre maio e setembro daquele ano, concluindo que essa inversão foi regida fundamentalmente por um único movimento, a implementação da segunda etapa do Plano Real, "com a troca da moeda e a queda abrupta da inflação (...) todos os acontecimentos amplificaram o efeito do Plano

3 Esta revisão é baseada em Carreirão, Yan de Souza. "Avaliação do Governo e Voto Econômico", Lua Nova, Revista de Cultura e Política, São Paulo, n. 48, 1999. 
Real no processo eleitoral" (Mendes e Venturi, 1994: 40; citado por Carreirão, 2000: 20).

Albuquerque (1995) investiga o impacto do Plano Real na eleição de 1994. O autor contesta a hipótese do "voto retrospectivo", dando mais ênfase à associação existente entre o voto e expectativa de resultados, "voto prospectivo".

Meneguello (1995) afirma que a vitória de Fernando Henrique em 1994 demonstrou o apoio do eleitorado ao Plano Real. Singer (1999) destaca, além da identificação ideológica, a importância do Plano Real na eleição presidencial de 1994. Carreirão (2000) analisou a relação entre desempenho econômico do governo e o voto nas eleições presidenciais de 1989, 1994 e 1998, concluindo que na eleição de 1994 e de 1998 o Plano Real foi definitivo para a vitória de Fernando Henrique.

Kinzo (1996) destaca em seu estudo sobre a eleição presidencial de 1994 que a vitória de Cardoso não se deu somente pelo desempenho do Plano Real mas também pela imagem política associada a Fernando Henrique.

\section{O contexto da eleição presidencial de $1998^{4}$}

Para o entendimento do cenário eleitoral de 1998 foi necessário recuarmos no tempo até a eleição de 1994 e observar os principais acontecimentos políticos, sociais e econômicos.

Os dois candidatos mais cotados nas pesquisas de intenção de voto, no final da campanha eleitoral de 94, eram, de um lado, Fernando Henrique Cardoso (PSDB), ex-senador, ex-ministro da economia, de outro, Luis Inácio Lula da Silva (PT), que voltava para sua segunda disputa presidencial, após o êxito de ter ido para o segundo turno na eleição presidencial de 1989 contra Collor e quase vencer o pleito. O resultado das urnas deu a Fernando Henrique, ainda no primeiro turno, o cargo de presidente da República.

4 Baseado Silva, Paulo Sérgio da. "Horário Eleitoral Gratuito e as Estratégias de Campanha da Eleição Presidencial de 1998”, Revista Teoria \& Pesquisa, n. 36-7, janeiro-junho de 2001, UFSCar, São Carlos, SP. 
Segundo Singer (1999), a campanha de 1994 se dividiu em duas etapas distintas. A primeira, que vai até julho de 1994, e uma segunda que se estendeu de julho a outubro. Na primeira etapa Fernando Henrique Cardoso tendeu a unificar em torno de si parte do voto da direita e do voto do centro; do ponto de vista social recebeu apoio dos estratos de maior renda. Já a segunda fase da campanha iniciou-se com a entrada em vigor do Plano Real, em 1 de julho de 1994. Os preços caíram, paralelamente a isso os índices de intenção de voto em Fernando Henrique Cardoso subiram e os de Lula começaram a cair.

O principal pilar da campanha de 94 foi o Plano Real, elaborado com a finalidade de solucionar a inflação, um problema histórico do país, a partir da estabilidade da economia.

Do ponto de vista econômico, depois de um ano de governo e do Plano Real, a inflação caiu de $941 \%$ para $23 \%$, o Produto Interno Bruto (PIB) subiu de 531 para 552 bilhões de dólares e as reservas internacionais pularam de 36 para 56 bilhões de dólares.

Em outubro de 1997 a Tailândia desvalorizou sua moeda provocando a quebra da bolsa de valores em muitos países, instaurando a chamada "Crise da Ásia". Foi um momento de tensão na economia brasileira, pois o Plano Real, tão elogiado, encontrava-se ameaçado. O governo, preocupado com a crise, lançou um pacote fiscal com 51 medidas para que o "Real" não fosse desvalorizado e a inflação não voltasse. A inflação não voltou com o terremoto da crise cambial da Ásia, no entanto o país perdeu cerca de 10 bilhões de dólares.

\section{Momento Pré-Eleitoral}

O momento pré-eleitoral (de março ao início de julho de 1998) foi caracterizado por uma avaliação negativa do governo por parte da mídia e pela ascensão do candidato Lula nas pesquisas de intenção de voto, de $23 \%$ (em maio de 98 ) para $28 \%$ (em julho de 98 ), ver gráfico 1. 
Gráfico 1

Evolução da intenção de voto (\%)* 1998 - IBOPE

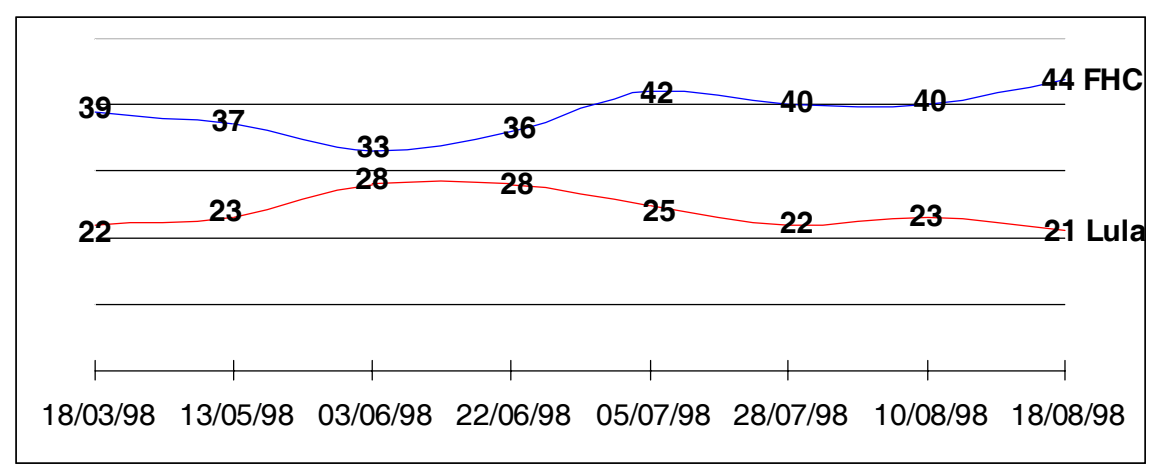

Fonte: Revista Veja , 26/08/98.

* Não estão incluídos as porcentagem dos indecisos, brancos/ nulos, de Ciro e de Enéas.

Ainda neste período em questão, tomando conhecimento da queda da popularidade nas pesquisas, o presidente Fernando Henrique, que pretendia a reeleição, começou definitivamente a arregaçar as mangas para o início da campanha. Começou a viajar pelo país tocando as obras do projeto "Brasil em Ação" e a preparar seu exército de especialistas que iria assessorá-lo.

Em julho Lula caiu nas pesquisas de intenção de voto, nunca mais alcançando Fernando Henrique, como mostra o gráfico 1.

No dia primeiro de julho de 1998 o Plano Real completou quatro anos e foi comemorado através de uma cerimônia pública pelo Presidente. Na época, foi lançado um novo conjunto de novas moedas ao custo de 326 milhões de reais e o brasileiro passou a manuseá-las, o que serviu como um lembrete do controle da inflação.

No aspecto político, Fernando Henrique teve que controlar as divergências existentes dentro do próprio quadro governista e também descartar a possibilidade de Paulo Maluf (PPB) em candidatar-se à Presidência da República, convencendo-o a disputar o governo de São Paulo, prometendo, em troca, ficar neutro na disputa com Mário Covas. Neutralidade que permaneceu apenas até a sua vitória, pois no segundo turno da eleição do Estado o Presidente se manifestou claramente em favor de Covas. O partido de Fernando Henrique, o PSDB, 
conseguiu realizar uma aliança que resultou na coligação chamada "União, Trabalho e Progresso" (PSDB - PFL - PPB e PTB). Desta maneira, Fernando Henrique manteve a aliança com o PFL e recebeu o apoio do líder político da Bahia, Antônio Carlos Magalhães.

Já do lado da oposição, a candidatura de Lula apresentava-se instável no início do ano de 1998 uma vez que, diziam os boatos da imprensa, ele não queria candidatar-se. Mas, pela pressão do próprio do $\mathrm{PT}$, que não tinha outro candidato competitivo, o líder petista aceitou concorrer. O PT conseguiu se aliar com o PDT de Brizola e enfrentou alguns obstáculos. Ao se coligar com Lula o PDT exigiu do PT que não lançasse candidato ao governo do Rio de Janeiro e também que apoiasse a candidatura de Antony Garotinho. Mas o PT do Rio resolveu refugar esse compromisso e lançou candidato próprio. Tão logo Lula declarou que retiraria sua candidatura, caso perdesse a aliança com o PDT carioca, o PT cancelou a candidatura própria para o governo do Rio. A partir desse fato a aliança entre os dois partidos se consolidou e foi lançada a coligação "União do Povo Muda Brasil" (PT - PDT - PC do B e PCB).

\section{Avaliação do desempenho o Plano Real}

\section{As hipóteses sobre o comportamento eleitoral de 1998}

Do banco de dados do "survey" sobre a eleição presidencial brasileira de 1998, foram extraídas sete variáveis para o propósito deste trabalho: 1) escolha eleitoral; 2) avaliação do custo e benefício que o Plano Real trouxe para o país; 3) avaliação do custo e benefício pessoal que o Plano Real trouxe; 4) identidade ideológica; 5) identidade partidária; 6) renda familiar; 7) e escolaridade.

A seguir realizamos os testes das hipóteses deste trabalho, através dos cruzamentos das variáveis envolvidas. A técnica estatística empregada é o cálculo dos coeficientes de associação $P$ hi. ${ }^{5}$

H1: O voto está associado ou não à avaliação do custo e benefício que o Plano Real trouxe para o país

5 A escala usada é a seguinte: <.3 (muito fraca); .3 a.6 (moderada); .7 a.9 (alta); $>.09$ (muito alta). 
Tabela 1 Voto nos candidatos em 1998 por benefício do Plano Real para o Brasil

\begin{tabular}{|l|c|c|c|c|c|c|c|}
\hline Porcentagem & \multicolumn{7}{|c|}{ Benefício do Plano Real para o Brasil } \\
\cline { 2 - 8 } $\begin{array}{l}\text { Resíduo } \\
\text { Ajustado }\end{array}$ & $\begin{array}{c}\text { Muito } \\
\text { Prejuízo }\end{array}$ & 2 & 3 & 4 & $\begin{array}{c}\text { Muito } \\
\text { Benefício }\end{array}$ & NS & Total \\
\hline FHC & 8,0 & 11,2 & 34,8 & 57,7 & 71,4 & 63,6 & 49,1 \\
& $-10,5$ & $-9,1$ & $-7,3$ & 4,5 & 13,4 & 1,0 & \\
\hline Lula & 62,7 & 64,9 & 44,1 & 25,4 & 14,4 & 18,2 & 32,4 \\
& 8,3 & 8,4 & 6,4 & $-3,9$ & $-11,5$ & 1,0 & \\
\hline Outros & 29,3 & 23,9 & 21,0 & 16,9 & 14,1 & 18,2 & 18,5 \\
& 3,5 & 1,6 & 1,6 & $-1,1$ & $-3,4$ &, 0 & \\
\hline N & 150 & 134 & 485 & 504 & 609 & 11 & 1893 \\
\hline Total & 100 & 100 & 100 & 100 & 100 & 100 & 100 \\
\hline Phi $=.446$ & & & & & & & \\
\hline
\end{tabular}

Fonte: Pesquisa sobre a eleição presidencial de 1998, coordenada por José Augusto Guilhon Albuquerque,

Núcleo Pesquisas em Relações Internacionais da Universidade de São Paulo.

Dentre os entrevistados que acham que o Plano Real trouxe muito benefício para o Brasil, 71,4\% são eleitores de Fernando Henrique Cardoso contra $14,4 \%$ de Lula. Ou seja, a maioria dos entrevistados que vê o benefício do Plano Real para o Brasil é eleitor de Fernando Henrique. Dentre os entrevistados que entendem que o Plano Real trouxe muito prejuízo para o Brasil, os eleitores de Lula são a maioria. $\mathrm{Na}$ avaliação de número três na escala, que é o meio termo, encontramos quase um empate entre os eleitores de Lula e os de Fernando Henrique.

Observando o coeficiente de associação entre as variáveis voto e avaliação de custo e benefício do Plano Real para o Brasil, podemos dizer que há associação. $\mathrm{O}$ valor de phi mostra que se trata de uma correlação moderada, de acordo com a nossa escala usada.

H2: O voto está associado ou não à avaliação de custo e benefício pessoal trazido pelo Plano Real aos indivíduos; 
Tabela 2 Voto nos candidatos em 1998 por benefício pessoal do Plano Real

\begin{tabular}{|l|c|c|c|c|c|c|c|}
\hline Porcentagem & \multicolumn{7}{|c|}{ Benefício do Plano Real para o Brasil } \\
\cline { 2 - 8 } $\begin{array}{l}\text { Resíduo } \\
\text { Ajustado }\end{array}$ & Muito & 2 & 3 & 4 & $\begin{array}{c}\text { Muito } \\
\text { Benefício }\end{array}$ & NS & Total \\
\hline FHC & 13,5 & 21,2 & 40,1 & 59,0 & 74,8 & 46,7 & 49,1 \\
& $-10,4$ & $-8,3$ & $-4,9$ & 5,0 & 13,2 &,- 2 & \\
\hline Lula & 57,0 & 54,0 & 39,2 & 26,8 & 12,0 & 26,7 & 32,4 \\
& 7,7 & 6,9 & 3,9 & $-3,0$ & $-11,1$ &,- 5 & \\
\hline Outros & 29,5 & 24,7 & 20,7 & 14,2 & 13,2 & 26,7 & 18,5 \\
& 4,1 & 2,4 & 1,5 & $-2,8$ & $-3,5$ &, 8 & \\
\hline N & 193 & 198 & 531 & 471 & 485 & 15 & 1893 \\
\hline Total & 100 & 100 & 100 & 100 & 100 & 100 & 100 \\
\hline Phi $=.421$ & & & & & & & \\
\hline
\end{tabular}

Fonte: Pesquisa sobre a eleição presidencial de 1998, coordenada por José Augusto Guilhon Albuquerque do Núcleo de Pesquisa em Relações Internacionais da Universidade de São Paulo.

Quando cruzamos a variável voto por avaliação do benefício $e$ prejuízo pessoal do Plano Real, a distribuição dos dados observados não se diferencia muito da tabela anterior. A maioria dos eleitores que acham que o Plano Real trouxe benefício pessoal é de Fernando Henrique, enquanto que a maioria que acha que o Plano Real trouxe muitos prejuízos pessoais é de Lula.

Olhando para o coeficiente de associação, vemos que o valor de phi mostra que a associação é moderada. Dessa forma, podemos afirmar que há associação entre a variável voto e avaliação de benefício $e$ prejuízo pessoal do Plano Real.

H3: A avaliação do custo e benefício do Plano Real está associada ou não à identidade partidária dos indivíduos; 
Tabela 3 Benefício do Plano Real para o Brasil por Identidade Partidária

\begin{tabular}{|c|c|c|c|c|c|c|c|c|}
\hline \multirow{2}{*}{\begin{tabular}{|l} 
Porcentagem Coluna \\
Resíduo Ajustado \\
Benefício do Plano \\
Real para o Brasil
\end{tabular}} & \multicolumn{8}{|c|}{ Identidade Partidária } \\
\hline & PSDB & PT & PMDB & PFL & PDT & Outros & Nenhum & Total \\
\hline Muito & 2,5 & 13,9 & 5,3 & ,6 & 13,7 & 10,5 & 7,3 & 8,0 \\
\hline Prejuízo & $-4,0$ & 6,3 & $-2,3$ & $-3,6$ & 1,8 & 1,3 &,- 7 & \\
\hline 2 & $\begin{array}{c}2,5 \\
-3,4\end{array}$ & $\begin{array}{c}12,3 \\
6,2\end{array}$ & $\begin{array}{c}5,1 \\
-1,7\end{array}$ & $\begin{array}{c}2.4 \\
-2,4\end{array}$ & $\begin{array}{c}11,0 \\
1,4\end{array}$ & $\begin{array}{l}8,9 \\
1,2\end{array}$ & $\begin{array}{c}5,1 \\
-2,0\end{array}$ & 6,9 \\
\hline 3 & $\begin{array}{l}18,5 \\
-3,5\end{array}$ & $\begin{array}{c}35,1 \\
5,7\end{array}$ & $\begin{array}{l}20,7 \\
-3,0\end{array}$ & $\begin{array}{l}18,2 \\
-2,5\end{array}$ & $\begin{array}{c}31,5 \\
1,0\end{array}$ & $\begin{array}{c}26,3 \\
-, 1\end{array}$ & $\begin{array}{c}27,7 \\
, 8\end{array}$ & 26,5 \\
\hline 4 & $\begin{array}{c}29,5 \\
1,0\end{array}$ & $\begin{array}{l}21,9 \\
-3,5\end{array}$ & $\begin{array}{c}30,6 \\
1,8\end{array}$ & $\begin{array}{c}25,5 \\
-, 5\end{array}$ & $\begin{array}{c}30,1 \\
.6\end{array}$ & $\begin{array}{c}23,2 \\
-1,3\end{array}$ & $\begin{array}{c}30,4 \\
2,0\end{array}$ & 27,1 \\
\hline Muito Benefício & $\begin{array}{c}46,5 \\
6,7\end{array}$ & $\begin{array}{l}15,9 \\
-9,3\end{array}$ & $\begin{array}{c}37,8 \\
3,6\end{array}$ & $\begin{array}{c}50,9 \\
5,9\end{array}$ & $\begin{array}{l}13,7 \\
-3,2\end{array}$ & $\begin{array}{c}30,0 \\
-, 2\end{array}$ & $\begin{array}{c}28,6 \\
-1,2\end{array}$ & 30,6 \\
\hline NS & $\begin{array}{r}, 6 \\
-, 5\end{array}$ & $\begin{array}{c}1,0 \\
, 2\end{array}$ & $\begin{array}{c}5 \\
-1,0\end{array}$ & $\begin{array}{l}2,4 \\
2,2\end{array}$ & $\begin{array}{c}, 0 \\
-, 8\end{array}$ & $\begin{array}{c}1,1 \\
, 3\end{array}$ & $\begin{array}{l}9 \\
, 0\end{array}$ & ,9 \\
\hline $\mathrm{N}$ & 325 & 627 & 434 & 165 & 73 & 190 & 573 & 2387 \\
\hline Total & 100 & & 100 & 100 & 100 & 100 & 100 & 100 \\
\hline Phi $=.337$ & & & & & & & & \\
\hline
\end{tabular}

Fonte: Pesquisa sobre a eleição presidencial de 1998, coordenada por José Augusto Guilhon Albuquerque do Núcleo de Pesquisas em Relações Internacionais da Universidade de São Paulo.

Podemos observar que a avaliação de custo e benefício do Plano Real, para o Brasil, está associada à identidade partidária. De acordo com a tabela 3, notamos que quase a metade dos entrevistados do PSDB e do PFL acham que o Pano Real trouxe muito benefício para o Brasil. Os eleitores do PMDB também, embora em menor porcentagem, concordam com isso. De maneira oposta, os eleitores do PT e do PDT acham que o Plano Real trouxe prejuízos para o país.

De acordo com o coeficiente de associação entre a variável avaliação de custo e benefício do Plano Real para o Brasil, podemos dizer que, embora não seja alto (indicando uma correlação moderada), o valor de associação deve ser considerado, o que significa que há associação entre achar que o Plano Real trouxe benefícios ou prejuízos para o Brasil e preferência partidária. 
Tabela 4 Benefício Pessoal do Plano Real por Identidade Partidária

\begin{tabular}{|c|c|c|c|c|c|c|c|c|}
\hline Porcentagem Coluna & \multicolumn{7}{|c|}{ Identidade Partidária } \\
\cline { 2 - 9 } \\
\cline { 2 - 9 } $\begin{array}{l}\text { Resíduo Ajustado } \\
\text { do Plano Real }\end{array}$ & PSDB & PT & PMDB & PFL & PDT & Outros & Nenhum & Total \\
\hline Muito & & & & & & & & \\
Prejuízo & 3,7 & 16,3 & 6,9 & 4,2 & 15,1 & 11,6 & 8,6 & 9,8 \\
\hline 2 & $-4,0$ & 6,4 & $-2,2$ & $-2,5$ & 1,6 &, 9 & $-1,1$ & \\
\hline 3 & 5,8 & 17,5 & 8,3 & 5,5 & 8,2 & 11,6 & 8,4 & 10,5 \\
& $-2,9$ & 6,7 & $-1,6$ & $-2,2$ &,- 6 &, 5 & $-1,9$ & \\
\hline 4 & 19,7 & 31,9 & 28,1 & 24,2 & 39,7 & 27,4 & 33,2 & 29,2 \\
& $-4,1$ & 1,7 &,- 6 & $-1,5$ & 2,0 &,- 6 & 2,4 & \\
\hline Muito Benefício & 31,1 & 21,4 & 26,5 & 27,9 & 24,7 & 23,2 & 26,7 & 25,6 \\
& 2,4 & $-2,8$ &, 5 &, 7 &,- 2 &,- 8 &, 7 & \\
\hline NS & 39,1 & 12,1 & 30,0 & 36,4 & 11,0 & 24,7 & 22,7 & 24,2 \\
& 6,7 & $-8,2$ & 3,1 & 3,8 & $-2,7$ &, 2 & $-1,0$ & \\
\hline N &, 6 &, 8 &, 2 & 1,8 & 1,4 & 1,6 &, 5 &, 8 \\
\hline Total &,- 3 &, 1 & $-1,4$ & 1,6 &, 6 & 1,4 &,- 7 & \\
\hline Phi =.305 & 325 & 627 & 434 & 165 & 73 & 190 & 573 & 2387 \\
\hline
\end{tabular}

Fonte: Pesquisa sobre a eleição presidencial de 1998, coordenada por José Augusto Guilhon Albuquerque do Núcleo de Pesquisas em Relações Internacionais da Universidade de São Paulo.

A leitura similar à da tabela 3 pode ser efetuada na tabela acima, pois, como vemos, os eleitores do PSDB e PFL acham que o Plano Real trouxe muitos benefícios pessoais, enquanto que os eleitores do PT e PDT acreditam que o Plano Real trouxe prejuízos pessoais.

O coeficiente de associação é maior quando cruzamos a variável avaliação de custos e benefícios para o Brasil com identidade ideológica (ver tabela 5), do que quando cruzamos a variável avaliação custos e benefícios pessoais, trazidos pelo Real, com identidade partidária. Todavia, não podemos descartar a associação deste último cruzamento.

H4: A avaliação do custo e benefício do Plano Real está associada ou não à identidade ideológica; 
Tabela 5 Benefício do Plano Real para o Brasil por Ideologia

\begin{tabular}{|c|c|c|c|c|}
\hline \multirow{2}{*}{$\begin{array}{l}\text { Porcentagem Coluna } \\
\text { Resíduo Ajustado } \\
\text { Benefício do Plano } \\
\text { Real para o Brasil }\end{array}$} & \multicolumn{4}{|c|}{ Ideologia } \\
\hline & Esquerda & Centro & Direita & Total \\
\hline Muito & 18,4 & 5,5 & 6,1 & 8,1 \\
\hline Prejuízo & 8,4 & $-4,0$ & $-2,7$ & \\
\hline \multirow[t]{2}{*}{2} & 12,8 & 7,2 & 3,1 & 6,7 \\
\hline & 5,5 & ,8 & $-5,3$ & \\
\hline \multirow[t]{2}{*}{3} & 33,1 & 30,5 & 19,7 & 26,9 \\
\hline & 3,1 & 3,3 & $-5,9$ & \\
\hline \multirow[t]{2}{*}{4} & 16,7 & 32,1 & 25,3 & \\
\hline & $-5,1$ & 5,1 & $-1,1$ & \\
\hline \multirow[t]{2}{*}{ Muito Benefício } & 17,9 & 24,6 & 45,4 & 31,1 \\
\hline & $-6,4$ & $-5,8$ & 11,2 & \\
\hline \multirow[t]{2}{*}{ NS } & 1,2 & ,2 & ,5 &, 5 \\
\hline & 2,3 & $-1,7$ &,- 1 & \\
\hline $\mathrm{N}$ & 414 & 964 & 819 & 2197 \\
\hline Total & 100 & 100 & 100 & 100 \\
\hline Phi $=.340$ & & & & \\
\hline
\end{tabular}

Fonte: Pesquisa sobre a eleição presidencial de 1998, coordenada por José Augusto Guilhon Albuquerque do Núcleo de Pesquisas em Relações Internacionais da Universidade de São Paulo.

O nosso próximo passo foi verificar se existe associação entre a variável avaliação do benefício do Plano Real para o Brasil e ideologia. Conforme os dados da tabela 5 observamos que o centro ficou no meio termo, nem achou que o Plano Real trouxe muito benefício nem que trouxe muito prejuízo. A direita entendeu que o Plano Real trouxe muito benefício para o Brasil. A esquerda achou que o Plano Real trouxe muitos prejuízos para o país.

O coeficiente de associação entre o cruzamento das variáveis benefícios do Plano Real para o Brasil por ideologia mostra uma associação relevante entre estas variáveis. 
Tabela 6 Benefício Pessoal do Plano Real por Ideologia

\begin{tabular}{|c|c|c|c|c|}
\hline Porcentagem Coluna & \multicolumn{4}{|c|}{ Ideologia } \\
$\begin{array}{c}\text { Resíduo Ajustado } \\
\text { Benefício Pessoal } \\
\text { do Plano Real }\end{array}$ & Esquerda & Centro & Direita & Total \\
\cline { 2 - 5 } & & & & \\
\hline Muito & 20,8 & 6,6 & 8,2 & 9,9 \\
Prejuízo & 8,2 & $-4,5$ & $-2,1$ & \\
\hline 2 & 15,9 & 13,7 & 5,0 & 10,7 \\
& 3,9 & 3,4 & $-6,6$ & \\
\hline 3 & 32,9 & 32,7 & 22,5 & 28,9 \\
& 2,0 & 3,4 & $-5,1$ & \\
\hline 4 & 17,9 & 28,8 & 25,5 & 25,5 \\
& $-4,0$ & 3,1 &, 0 & \\
\hline Muito Benefício & 11,6 & 18,5 & 38,6 & 24,7 \\
& $-6,9$ & $-6,0$ & 11,7 & \\
\hline NS & 1,0 &, 2 &, 2 &, 4 \\
& 2,3 & $-1,1$ &,- 7 & \\
\hline N & 414 & 964 & 819 & 2197 \\
\hline Total & 100 & 100 & 100 & 100 \\
\hline Phi =.337 & & & & \\
\hline
\end{tabular}

Fonte: Pesquisa sobre a eleição presidencial de 1998, coordenada por José Augusto Guilhon Albuquerque do Núcleo de Pesquisas em Relações Internacionais da Universidade de São Paulo.

Medimos também a associação entre a variável avaliação dos custos e benefícios pessoais do Plano Real e ideologia. De acordo com a tabela 6, percebemos que a avaliação da esquerda indica que houve mais prejuízos do que benefícios pessoais trazidos pelo Plano Real. A direita, de forma oposta, acha que os benefícios pessoais que o Plano Real trouxe foram maiores do que os prejuízos. Observamos ainda que o centro se apresentou mais insatisfeito perante os benefícios pessoais trazidos pelo Plano Real do que em relação aos benefícios que o Plano trouxe para o Brasil.

H5: A avaliação de custo e benefício do Plano Real está associada ou não à renda familiar; 
Tabela 7 Benefício do Plano Real para o Brasil por Renda Familiar

\begin{tabular}{|c|c|c|c|c|c|c|c|}
\hline \multirow{2}{*}{$\begin{array}{c}\text { Porcentagem } \\
\text { Coluna } \\
\text { Resíduo Ajustado } \\
\text { Benefício do Plano }\end{array}$} & \multicolumn{7}{|c|}{ Renda Familiar } \\
\cline { 2 - 8 } Real para o Brasil & $\begin{array}{c}\text { Não } \\
\text { Informou }\end{array}$ & 1 a 3 SM & 4 a 5 SM & 6 a 7 SM & 8 a 10 SM & $\begin{array}{c}\text { Acima de } \\
10 \text { SM }\end{array}$ & Total \\
\hline Muito & 11,9 & 7,9 & 8,0 & 7,5 & 6,3 & 7,8 & 7,9 \\
Prejuízo & 1,9 &, 0 &, 1 &,- 3 & $-1,1$ &,- 1 & \\
\hline 2 & 4,4 & 7,0 & 7,4 & 6,4 & 5,6 & 7,8 & 6,8 \\
& $-1,3$ &, 3 &, 5 &,- 3 &,- 9 & 1,0 & \\
\hline 3 & 32,5 & 3,9 & 28,1 & 26,9 & 28,3 & 25,7 & 26,7 \\
& 1,7 & $-1,8$ &, 8 &, 1 &, 7 &,- 5 & \\
\hline 4 & 23,1 & 28,9 & 24,7 & 27,2 & 27,0 & 27,7 & 27,0 \\
& $-1,1$ & $-1,3$ & $-1,2$ &, 1 &, 0 &, 4 & \\
\hline Muito Benefício & 28,1 & 30,8 & 30,7 & 31,7 & 31,9 & 30,5 & 30,8 \\
&,- 8 &, 0 &, 0 &, 4 &, 4 &,- 2 & \\
\hline NS &, 0 & 1,5 & 1,1 &, 3 & 1,0 &, 4 &, 8 \\
& $-1,2$ & 2,1 &, 6 & $-1,3$ &, 3 & $-1,2$ & \\
\hline N & 160 & 598 & 462 & 360 & 304 & 501 & 2385 \\
\hline Total & 100 & 100 & 100 & 100 & 100 & 100 & 100 \\
\hline Phi =.098 & & & & & & & \\
\hline
\end{tabular}

Fonte: Pesquisa sobre a eleição presidencial de 1998, coordenada por José Augusto Guilhon Albuquerque do Núcleo de Pesquisas em Relações Internacionais da Universidade de São Paulo.

Tabela 8 Benefício Pessoal do Plano Real por Renda Familiar

\begin{tabular}{|c|c|c|c|c|c|c|c|}
\hline \multirow{2}{*}{$\begin{array}{c}\text { Porcentagem } \\
\text { Coluna } \\
\text { Resíduo Ajustado } \\
\text { Benefício Pessoal } \\
\text { do Plano Real }\end{array}$} & \multicolumn{7}{|c|}{ Renda Familiar } \\
\cline { 2 - 8 } & $\begin{array}{c}\text { Não } \\
\text { Informou }\end{array}$ & 1 a 3 SM & 4 a 5 SM & 6 a 7 SM & 8 a 10SM & $\begin{array}{c}\text { Acima de } \\
10 \text { SM }\end{array}$ & Total \\
\hline Muito & 14,4 & 11,0 & 7,8 & 9,2 & 8,2 & 9,4 & 9,6 \\
Prejuízo & 2,1 & 1,3 & $-1,5$ &,- 3 & $-0,9$ &,- 2 & \\
\hline 2 & 6,9 & 9,7 & 10,6 & 9,7 & 10,2 & 13,4 & 10,5 \\
& $-1,6$ &,- 8 &, 1 &,- 5 &,- 2 & 2,3 & \\
\hline 3 & 31,9 & 29,9 & 31,6 & 26,1 & 29,6 & 27,3 & 29,2 \\
&, 8 &, 4 & 1,3 & $-1,4$ &, 2 & $-1,0$ & \\
\hline 4 & 25,6 & 26,1 & 23,6 & 28,9 & 27,0 & 25,7 & 26,0 \\
&,- 1 &, 0 & $-1,3$ & 1,3 &, 4 &,- 2 & \\
\hline Muito Benefício & 20,6 & 22,4 & 25,3 & 25,8 & 24,0 & 24,0 & 23,9 \\
& $-1,0$ & 1,0 &, 8 &, 9 &, 0 &, 0 & \\
\hline NS &, 6 & 0,8 & 1,1 &, 3 & 1,0 &, 2 &, 7 \\
&,- 1 &, 6 & 1,2 & $-1,0$ &, 7 & $-1,5$ & \\
\hline N & 160 & 598 & 462 & 360 & 304 & 501 & 2385 \\
\hline Total & 100 & 100 & 100 & 100 & 100 & 100 & 100 \\
\hline Phi =.104 & & & & & & & \\
\hline
\end{tabular}

Fonte: Pesquisa sobre a eleição presidencial de 1998, coordenada por José Augusto Guilhon Albuquerque do Núcleo de Pesquisas em Relações Internacionais da Universidade de São Paulo. 
H6: A avaliação do custo e benefício do Plano Real está associada ou não à escolaridade dos entrevistados

Tabela 9 Benefício do Plano Real para o Brasil por Escolaridade

\begin{tabular}{|c|c|c|c|c|c|}
\hline $\begin{array}{c}\text { Porcentagem } \\
\text { Coluna } \\
\text { Resíduo Ajustado }\end{array}$ & \multicolumn{5}{|c|}{ Escolaridade } \\
\hline $\begin{array}{c}\text { Benefício do Plano } \\
\text { Real para o Brasil }\end{array}$ & $\begin{array}{c}\text { Analfabeto } \\
\text { ao Primário }\end{array}$ & 1 Grau & II Grau & Superior & Total \\
\hline Muito & 7,0 & 8,5 & 8,2 & 7,1 & 7,9 \\
Prejuízo &,- 8 &, 7 &, 4 &,- 6 & \\
\hline 2 & 7,2 & 6,4 & 5,9 & 9,0 & 6,7 \\
&, 5 &,- 4 & $-1,2$ & 1,7 & \\
\hline 3 & 23,3 & 24,6 & 30,4 & 25,6 & 26,6 \\
& $-1,8$ & $-1,6$ & 3,3 &,- 4 & \\
\hline 4 & 27,0 & 26,5 & 27,7 & 26,9 & 27,1 \\
&, 0 &,- 5 &, 5 &,- 1 & \\
\hline Muito Benefício & 33,6 & 33,4 & 27,0 & 31,1 & 30,8 \\
& 1,5 & 1,9 & $-3,1$ &, 1 & \\
\hline NS & 1,9 &, 6 &, 7 &, 3 &, 8 \\
& 2,7 &,- 8 &,- 7 & $-1,1$ & \\
\hline N & 485 & 797 & 910 & 312 & 2504 \\
\hline Total & 100 & 100 & 100 & 100 & 100 \\
\hline Phi =.106 & & & & & \\
\hline
\end{tabular}

Fonte: Pesquisa sobre a eleição presidencial de 1998, coordenada por José Augusto Guilhon Albuquerque do Núcleo Pesquisas em Relações Internacionais da Universidade de São Paulo. 
Tabela 10 Benefício Pessoal do Plano Real por Escolaridade

\begin{tabular}{|c|c|c|c|c|c|}
\hline Porcentagem & \multicolumn{5}{|c|}{ Escolaridade } \\
\hline $\begin{array}{c}\text { Benefício Pessoal } \\
\text { do Plano Real }\end{array}$ & $\begin{array}{l}\text { Analfabeto } \\
\text { ao Primário }\end{array}$ & 1 Grau & II Grau & Superior & Total \\
\hline $\begin{array}{c}\text { Muito } \\
\text { Prejuízo }\end{array}$ & $\begin{array}{c}10,1 \\
, 3\end{array}$ & $\begin{array}{c}9,8 \\
, 0\end{array}$ & $\begin{array}{l}9,6 \\
-, 3\end{array}$ & $\begin{array}{c}9,9 \\
, 1\end{array}$ & 9,8 \\
\hline 2 & $\begin{array}{r}8,5 \\
-1,5\end{array}$ & $\begin{array}{c}9,0 \\
-1,4\end{array}$ & $\begin{array}{c}11,6 \\
1,7\end{array}$ & $\begin{array}{c}12,5 \\
1,4\end{array}$ & 10,3 \\
\hline 3 & $\begin{array}{c}28,7 \\
-, 4\end{array}$ & $\begin{array}{c}29,9 \\
, 4\end{array}$ & $\begin{array}{c}29,5 \\
, 1\end{array}$ & $\begin{array}{c}28,5 \\
-, 3\end{array}$ & 29,3 \\
\hline 4 & $\begin{array}{c}24,9 \\
-, 5\end{array}$ & $\begin{array}{l}23,7 \\
-1,7\end{array}$ & $\begin{array}{c}28,4 \\
2,1\end{array}$ & $\begin{array}{c}25,6 \\
-, 1\end{array}$ & 25,9 \\
\hline Muito Benefício & $\begin{array}{c}26,6 \\
1,5\end{array}$ & $\begin{array}{l}26,7 \\
2,2\end{array}$ & $\begin{array}{l}20,5 \\
-3,1\end{array}$ & $\begin{array}{c}23,1 \\
-, 4\end{array}$ & 24,0 \\
\hline NS & $\begin{array}{l}1,2 \\
1,5\end{array}$ & $\begin{array}{l}, 9 \\
, 6\end{array}$ & $\begin{array}{c}, 4 \\
-1,2\end{array}$ & $\begin{array}{l}, 3 \\
-, 9\end{array}$ & ,7 \\
\hline $\mathrm{N}$ & 485 & 797 & 910 & 312 & 2504 \\
\hline Total & 100 & 100 & 100 & 100 & 100 \\
\hline Phi $=.094$ & & & & & \\
\hline
\end{tabular}

Fonte: Pesquisa sobre a eleição presidencial de 1998, coordenada por José Augusto Guilhon Albuquerque do Núcleo Pesquisas em Relações Internacionais da Universidade de São Paulo.

O cruzamento da variável benefício do Plano Real para o Brasil com renda familiar, bem como o cruzamento do benefício do Plano Real para o Brasil com a escolaridade dos entrevistados não apresentou associação. $\mathrm{O}$ coeficiente de associação phi, em ambos os cruzamentos, pode ser considerado desprezível. Ou seja, a avaliação do benefício do Plano Real para o Brasil não pode ser explicada nem pela renda familiar nem pela escolaridade dos entrevistados.

A variável avaliação dos benefícios pessoais, trazida pelo Plano Real, não tem relação com as variáveis renda familiar e escolaridade dos entrevistados. Os coeficientes de associação podem ser descartados.

Portanto, podemos concluir que nem a variável renda familiar, nem a variável escolaridade devem ser vistas como variáveis explicativas para a avaliação do custo e benefício trazidos pelo Plano Real, tanto do ponto de vista da avaliação pessoal como para a situação do país. 


\section{Conclusão}

Os resultados encontrados permitem afirmar que o comportamento dos eleitores na eleição de 1998 pode ser explicado, em parte, pela avaliação que o eleitor faz do custo e benefício do Plano Real. Também nos admitem dizer que o eleitor não só avalia o custo e benefício pessoal que o Plano Real trouxe, como também avalia o custo e o benefício que o Plano Real trouxe para o país.

Desta forma, o eleitor, ao votar, não apenas pensa em si próprio, como Downs (1999) sugere, mas se preocupa também com a situação do país ("sociotropic voting"). Ou seja, os resultados deste trabalho corroboram os pressupostos comuns, tanto de Downs ("teoria econômica do voto"), como dos teóricos do "modelo economicista" de explicação do voto, que admitem que os eleitores avaliam os custos e benefícios antes de votar.

Foi possível também investigar a que outros elementos estão ligados a variável que explica o voto, isto é, a avaliação de custo e benefício que o Plano Real trouxe para o eleitor e para o país. Os resultados encontrados indicam associação entre as variáveis avaliação de custo $e$ benefício pessoal e para o país, do Plano Real, e identidade partidária e identidade ideológica dos entrevistados.

Mas os dados sinalizam quase nenhuma associação entre a avaliação de custo e benefício, pessoal e para o país, trazido pelo Plano Real, à renda familiar e à escolaridade dos entrevistados.

A questão da maximização do voto, que é um dos pressupostos da "teoria econômica downsiana" do voto, em que o indivíduo busca maximizar seu voto em uma eleição ou votar no candidato ou partido que trará, no futuro, maior benefício, não foi foco de atenção deste trabalho. No entanto, seria interessante testar as hipóteses do "voto retrospectivo" e do "voto prospectivo", nesta eleição. Acreditamos que é possível tomar em comum o pressuposto de que o eleitor avalia os custos e benefícios da política econômica do governo tanto para a "teoria economicista" como para a "teoria econômica" de Downs.

Os resultados encontrados aqui se fazem importantes porque contribuem para a concepção de que não devemos deixar de lado a identidade partidária e nem a identidade política - ideológica ao estudarmos o comportamento eleitoral. Da mesma maneira também acreditamos que o trabalho contribui para chamar atenção para a validade 
dos pressupostos da "teoria econômica" e da "teoria economicista" para a explicação do comportamento eleitoral brasileiro.

\section{Referências bibliográficas}

Carreirão, Yan de Souza. A Decisão do voto nas eleições presidenciais no Brasil (1989 a 1998): a importância do voto por avaliação de desempenho. Tese (Doutorado), São Paulo, dezembro de 2000. Mimeografado.

. Avaliação do governo e voto econômico. Lua Nova, Revista de Cultura e Política. São Paulo, n. 48, 1999.

Campbell, Angus et allii. The american voter, Chicago. Chicago, 1980.

Downs, Antony. Uma teoria econômica da democracia. São Paulo: Edusp, 1999.

Figueiredo, Marcus. A decisão do voto. São Paulo: Editora Sumaré - ANPOCS, 1991.

FIORINA, Morris P. Retrospective voting in american national elections. New Haven: Yale University Press, 1981.

KInzo, Maria D’Alva Gil Kinzo. A eleição presidencial de 1994 no Brasil: Fernando Henrique e o Plano Real. In: Pinto, Céli Regina; Guerrero, Hugo (Orgs.). América Latina: o desafio da democracia nos anos 90. Porto Alegre, editora da UFRGS/Associação de Universidades Grupo Montevideo, 1996.

LEwIN, Jack. Estatística aplicada a ciências humanas, Ed. Harbra.

Nordhauss, William D. The political business cycle. Review of Economic Studies, 42, p. 169-90, 1957.

Meneguello, Raquel. Partidos e tendências de comportamento: o cenário em 1994. In: Dagnino, Evelina (Org.). Anos 90, política e sociedade no Brasil. São Paulo: Brasiliense, 1994.

Mendes, Antônio Manuel Teixeira; Venturi, Gustavo. Eleição presidencial: o Plano Real na sucessão de Itamar Franco. Opinião Pública, Campinas: Cesop, 2(2), 1994.

Muszynski, Judith; Mendes, Antônio Manuel Teixeira. Democratização e opinião pública no Brasil. In: LAmounier, Bolívar (Org.). De Geisel a Collor: o balanço da transição. São Paulo: Sumaré, 1990.

SANTOS, Wanderley Guilherme. Paradoxos do liberalismo - teoria e história. Rio de Janeiro: Vértice/IUPERJ, 1988.

SINGER, Vitor André. Esquerda e direita no eleitorado brasileiro. São Paulo: Edusp, 1999. 
SiLva, Paulo Sérgio da. Horário eleitoral gratuito e as estratégias de campanha da eleição presidencial de 1998. Revista Teoria \& Pesquisa, n. 36-7, jan-jun. de 2001, São Carlos, UFSCar. 